\title{
Prediction and Simulation of Elliptical Drawing Based on DYNAFORM
}

\author{
Jun Liu, Jiansheng Xia* and Bin Yuan \\ Yancheng Institute of Technology, Yancheng, 224051, China \\ ${ }^{*}$ Corresponding author
}

\begin{abstract}
Sheet metal stamping is an important method of plastic processing, which is one of the basic means of modern manufacturing industry. With the increasing demands of stamping quality, the production quality of stamping process optimization requirements are also rising. In this paper, finite element theory, the application of combination of dynamic display algorithm and static implicit algorithm, based on DYNAFORM platform, numerical simulation under different punch plate rounded, BHF, coefficient of friction, speed and other parameters of the stamping process have different influences on oval stretch formability. It offers good choice of selection of material, which reduces the costs of development of new products and shortens the manufacturing cycle of molds. It also provides some experience and help for oval deep drawing process in the future.
\end{abstract}

Keywords-stamping; DYNAFORM; process parameters; formability

\section{INTRODUCTION}

The numerical simulation technology of sheet metal forming in China is over 20 years later than the United States and Japan, of which development speed is very fast. As early as 1980s, Xiao put forward the theory of rigid plastic deformation theory of Kirchhoff [1].

End of 1980s, Zeng studied the law of metal deformation of rod-rod composite extrusion and cup extrusion [2].

At the beginning of 1990 s, the Xiong used the system of ADINA to simulate the forming of drawing, hydraulic bulging and air cover plate warm [3].

Zhang put forward the finite element analysis program of viscoplastic shell forming [4].

At the end of 1990s, Xu studied the rectangular box drawing, and simulated the crack, wrinkle and lug phenomenon of stretch forming [5].

In 2006, Jiang put forward the finite element method as the representative of the numerical simulation method for optimizating the process parameters in the forging deformation.

In 2010, Yu simulated the double drawing formability of the cylinder and predicted the performance based on DYNAFORM [7].

In 2013, Zhang designed and simulated the crack, wrinkle and springback of B pole stamping die, and provided the design basis for similar products [8].
The development of finite element analysis method in China is later than some developed countries, but it pay more and more attention to the numerical simulation technology. Some sheet CAE software have been developed in China, such as: SheetForm of Beijing University of Aeronautics and Astronautics, CASFORM of the Shandong University, MAFAP of Beijing Research Institute of Electrical Technology

\section{GENERAL STEPS OF FORMING SIMULATION IN DYNAFORM}

First, the 3D model of ellipse stretch die is designed based on NX and exported to DYNAFORM with the IGES files. Second, it is divided into 329 finite elements of which the quadrilateral element accounts for $99.1 \%$, and then the .dyn file is generated which is solved with double precision solution with LS-DYNA solver. Finally, the post-processing files are simulated with ETA/POST. The whole process is shown in figure I.

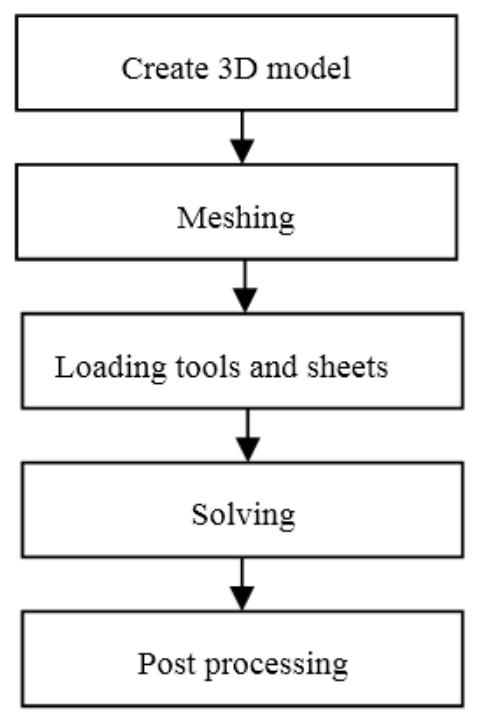

FIGURE I. SIMULATION FLOW CHART OF DYNAFORM

\section{TIME STEPS AND MASS SCALING}

The shell element is used to calculate the stamping process of DYNAFROM: 


$$
\Delta t=L_{S} / C
$$

Where $L_{s}$ is a unit characteristic length, $C$ is a propagation velocity of sound in this material and defined as follows:

$$
\mathrm{C}=\sqrt{\frac{\mathrm{E}}{\rho\left(1-\delta^{2}\right)}}
$$

Where $\mathrm{E}$ is young's modulus and $\delta$ is Poisson's ratio.

According to (1) and (2), the step time is proportional to the biggest feature length, and is proportional to square root of the density, the formula is as follows:

$$
\Delta t=L_{s} \sqrt{\rho\left(1-\delta^{2}\right) / E}
$$

Where $L_{s}$ is defined as follows:

$$
L_{S}=(1+\beta) A_{S} / \max \left(L_{1}, L_{2}, L_{3},(1-\beta) L_{4}\right)
$$

$\beta=0$ when quadrilateral elements and $\beta=1$ when triangular elements, $A_{s}$ is the unit area.

When calculating the time step, the system checks all units and determines the time step with the smallest unit length. The formula is as follows:

$$
\Delta t^{n+1}=\alpha \llbracket \min \left\{\Delta t_{1}, \Delta t_{2}, \Delta t_{3}, \ldots \ldots, \Delta t_{n}\right\}
$$

Where $\mathrm{n}$ is the unit number, $\alpha$ is a scaling factor for stabilizing calculation and generally takes $90^{\circ}$ or a smaller value.

The calculation time depends on the size of the smallest unit in the model, so the computation time of the whole model is obviously affected by the smaller units. In order to solve this problem, the concept of mass scaling is introduced.

The essence of mass scaling is to steady the calculation time of the model [10].

\section{Simulation AND Numerical ANALysis OF Stamping PROCESS PARAMETERS}

\section{A. Simulation Analysis of the Punch Fillet}

The material is DQSK (36), elliptical semimajor axis length is $15 \mathrm{~cm}$ and the short axle length is $12 \mathrm{~cm}$; punching stroke is $13 \mathrm{~cm}$; the friction coefficient is 0.125 ; the blank holding force is $2000 \mathrm{~N}$; the punch velocity is $5000 \mathrm{~m} / \mathrm{s}$ (virtual velocity). It analysis the tensile properties with different punch radius and the fillet sizes are set to three groups: $\mathrm{R}=6 \mathrm{~cm}, \mathrm{R}=7 \mathrm{~cm}, \mathrm{R}=8 \mathrm{~cm}$.

The effect of the punch radius on stamping formability is shown in Table I. The figure II is the result of three group experiments: FLD (a) and thickness (b).
TABLE I. EFFECT OF THE PUNCH RADIUS R ON STAMPING FORMABILITY

\begin{tabular}{|c|c|c|c|c|}
\hline Rarameter(\%) & $\begin{array}{c}\dot{\varepsilon}_{1} \\
\text { (Max } \\
\text { thinning } \\
\text { rate) }\end{array}$ & $\begin{array}{c}\dot{\varepsilon}_{2} \\
\text { (Max } \\
\text { thickening } \\
\text { rate) }\end{array}$ & $\begin{array}{c}\mathcal{E}_{\max } \\
\text { (Max } \\
\text { principal } \\
\text { strain) }\end{array}$ & $\begin{array}{c}\Delta \Gamma \\
\text { (Material } \\
\text { flow } \\
\text { difference) }\end{array}$ \\
\hline 6 & 10.79 & 4.22 & 0.11 & 1.05 \\
\hline 7 & 10.42 & 3.93 & 0.11 & 0.98 \\
\hline 8 & 10.72 & 3.74 & 0.11 & 0.73 \\
\hline
\end{tabular}

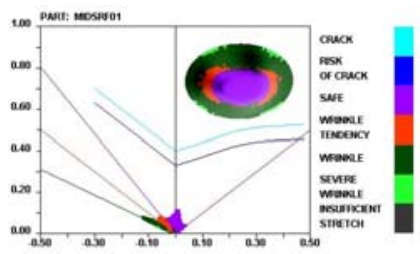

(a)

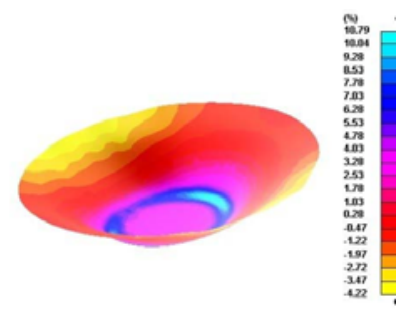

(b)
FIGURE II. ELLIPTIC DRAWING OF PUNCH RADIUS 6CM: (A)FORMING LIMIT DIAGRAM , (B) THICKNESS CHART

\section{B. Simulation Analysis of the Blank Holder Force}

The material is DQSK (36); elliptical semimajor axis length is $15 \mathrm{~cm}$ and the short axle length is $12 \mathrm{~cm}$; punching stroke is $13 \mathrm{~cm}$ (base on forming thickening not exceed than $5 \%$ and thinning not exceed $30 \%$ ), the friction coefficient is 0.125 ; punch radius is $7 \mathrm{~cm}$; stamping speed is $5000 \mathrm{~m} / \mathrm{s}$ (DYNAFORM speed); performance analysis of stretch forming of different BHF which are $1000 \mathrm{~N}, 2000 \mathrm{~N}, 3000 \mathrm{~N}, 4000 \mathrm{~N}$.

The effect of different holder force $\mathrm{F}$ on the forming performance is shown in table II. The ellipse drawing of the blank holder force $1000 \mathrm{~N}$ is shown in Figure III.

TABLE II. EFFECT OF BLANK HOLDER FORCE F ON STAMPING FORMABILITY

\begin{tabular}{|c|c|c|c|c|}
\hline Rarameter(\%) & $\begin{array}{c}\dot{\varepsilon}_{1} \\
\text { (Max } \\
\text { thinnin } \\
\text { g rate) }\end{array}$ & $\begin{array}{c}\dot{\varepsilon}_{2} \\
\text { (Max } \\
\text { thickeni } \\
\text { ng rate) }\end{array}$ & $\begin{array}{c}\boldsymbol{E}_{\max } \\
\text { (Max } \\
\text { principal } \\
\text { strain) }\end{array}$ & $\begin{array}{c}\Delta \Gamma \\
\text { (Material } \\
\text { flow } \\
\text { difference) }\end{array}$ \\
\hline 1000 & 10.42 & 3.93 & 0.11 & 0.98 \\
\hline 2000 & 10.42 & 3.93 & 0.11 & 0.98 \\
\hline 3000 & 10.41 & 3.92 & 0.11 & 0.98 \\
\hline 4000 & 10.40 & 3.91 & 0.11 & 0.98 \\
\hline
\end{tabular}

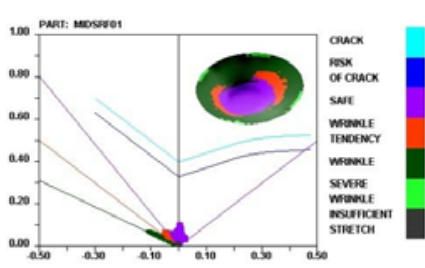

(a)

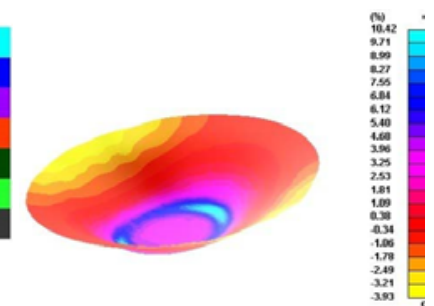

(b)
FIGURE III. DRAWING ANALYSIS OF BLANK HOLDER FORCE 1000N: (A)FORMING LIMIT DIAGRAM, (B) THICKNESS CHART 


\section{Simulation Analysis of the Friction Coefficient}

The material is DQSK (36); elliptical semimajor axis length is $15 \mathrm{~cm}$ and the short axle length is $12 \mathrm{~cm}$; punching stroke is $13 \mathrm{~cm}$ (based on forming thickening not more than 5\% and thinning not exceed $30 \%$ ); blank holder force $\mathrm{F}$ is $2000 \mathrm{~N}$; stamping speed is $5000 \mathrm{~m} / \mathrm{s}$ (DYNAFORM speed); performance analysis of stretch forming with different friction coefficient which are $0.075,0.1,0.125,0.15$.

The effect of different friction coefficient on the forming performance is shown in Table III. The result of friction coefficient 0.075 drawing is shown in Figure IV.

\section{TABLE III. EFFECT OF FRICTION COEFFICIENT U ON STAMPING} FORMABILITY

\begin{tabular}{|c|c|c|c|c|}
\hline Rarameter(\%) & $\begin{array}{c}\dot{\varepsilon}_{1} \\
\text { (Max } \\
\text { thinning } \\
\text { rate) }\end{array}$ & $\begin{array}{c}\dot{\varepsilon}_{2} \\
\text { (Max } \\
\text { thickening } \\
\text { rate) }\end{array}$ & $\begin{array}{c}\varepsilon_{\max } \\
\text { (max } \\
\text { principal } \\
\text { strain) }\end{array}$ & $\begin{array}{c}\Delta \Gamma \\
\text { (Material } \\
\text { flow } \\
\text { difference) }\end{array}$ \\
\hline 0.075 & 10.34 & 3.99 & 0.11 & 1.00 \\
\hline 0.1 & 10.38 & 3.96 & 0.11 & 0.99 \\
\hline 0.125 & 10.42 & 3.93 & 0.11 & 0.98 \\
\hline 0.15 & 10.47 & 3.90 & 0.11 & 0.98 \\
\hline
\end{tabular}

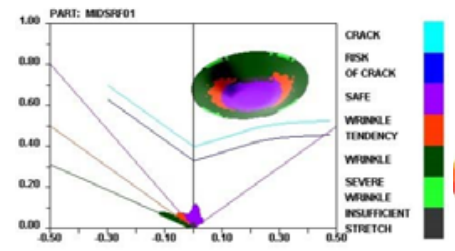

(a)

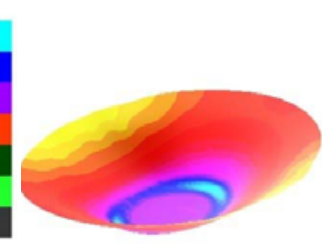

(b)

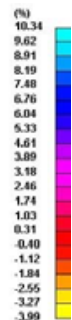

FIGURE IV. DRAWING ANALYSIS OF FRICTION COEFFICIENT 0.075:(A)FORMING LIMIT DIAGRAM (B) THICKNESS CHART

\section{Simulation Analysis of the Stamping Speed}

The material is DQSK (36); elliptical semimajor axis length is $15 \mathrm{~cm}$ and the short axle length is $12 \mathrm{~cm}$; punching stroke is $13 \mathrm{~cm}$ (based on forming thickening not more than $5 \%$ and thinning not exceed $30 \%$ ); friction coefficient is 0.125 ; stamping speed is $5000 \mathrm{~m} / \mathrm{s}$ (DYNAFORM speed); performance analysis of stretch forming with different stamping speed, which are $3000 \mathrm{~m} / \mathrm{s} 、 4000 \mathrm{~m} / \mathrm{s} 、 5000 \mathrm{~m} / \mathrm{s}$ 、 $5500 \mathrm{~m} / \mathrm{s}$.

TABLE IV. EFFECT OF TAMPING SPEED V ON STAMPING FORMABILITY

\begin{tabular}{|c|c|c|c|c|}
\hline Rarameter(\%) & $\begin{array}{c}\dot{\varepsilon}_{1} \\
\text { (Max } \\
\text { thinning } \\
\text { rate) }\end{array}$ & $\begin{array}{c}\dot{\varepsilon}_{2} \\
\text { (Max } \\
\text { thickening } \\
\text { rate) }\end{array}$ & $\begin{array}{c}\varepsilon_{\max } \\
\text { (max } \\
\text { principal } \\
\text { strain) }\end{array}$ & $\begin{array}{c}\Delta \Gamma \\
\text { (Material } \\
\text { flow } \\
\text { difference) }\end{array}$ \\
\hline 3000 & 10.46 & 4.00 & 0.11 & 0.97 \\
\hline 4000 & 10.45 & 3.96 & 0.11 & 0.97 \\
\hline 5000 & 10.42 & 3.93 & 0.11 & 0.98 \\
\hline 5500 & 10.41 & 3.93 & 0.11 & 0.97 \\
\hline
\end{tabular}

The effect of different speed on the forming performance is shown in Table IV. The result of the stamping speed $3000 \mathrm{~m} / \mathrm{s}$ is shown in Figure V.

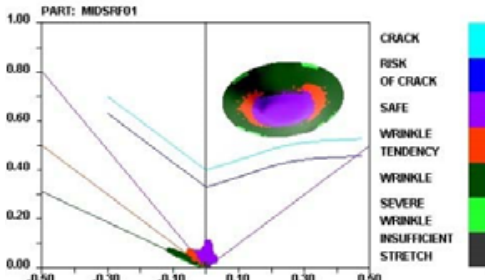

(a)

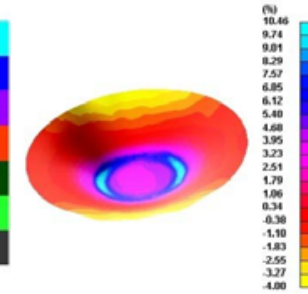

(b)
FIGURE V. DRAWING ANALYSIS OF STAMPING SPEED 3000M/S: (A)FORMING LIMIT DIAGRAM (B) THICKNESS CHART

\section{E. Simulation Analysis of Elliptical Eccentricity E}

The material is DQSK (36); punching stroke is $13 \mathrm{~cm}$ (based on forming thickening not more than 5\% and thinning not exceed $30 \%$ ); friction coefficient is 0.125 ; stamping speed is $5000 \mathrm{~m} / \mathrm{s}$ (DYNAFORM speed); the short axle and length axis of elliptical are shown as the table V.

The effect of Elliptical eccentricity on the forming performance is shown in Table VI. The result of Elliptical eccentricity 0.8 is shown in Figure VI.

TABLE V. PARAMETERS OF ELLIPTICAL SHEET WITH DIFFERENT ECCENTRICITY E

\begin{tabular}{|c|c|c|c|c|}
\hline Parameter & $\begin{array}{c}\text { a } \\
\text { (length } \\
\text { axis) }\end{array}$ & $\begin{array}{c}\text { b } \\
\text { (short } \\
\text { axle) }\end{array}$ & $\begin{array}{c}\text { c } \\
\text { (Focal half } \\
\text { distance) }\end{array}$ & $\begin{array}{c}\text { E } \\
\text { (Elliptical } \\
\text { eccentricity) }\end{array}$ \\
\hline 1 & 15 & 9 & 12 & 0.80 \\
\hline 2 & 15 & 12 & 9 & 0.60 \\
\hline 3 & 15 & 13.5 & 6.54 & 0.44 \\
\hline
\end{tabular}

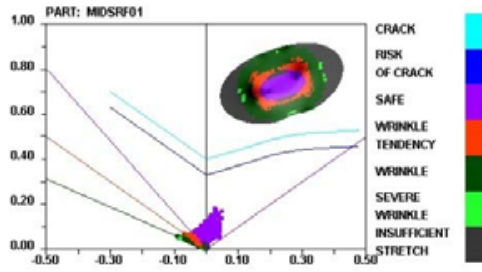

(a)

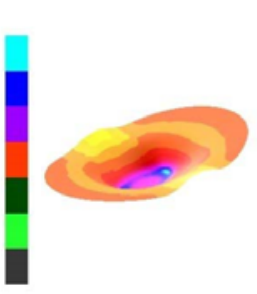

(b)

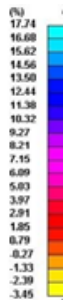

FIGURE VI. DRAWING ANALYSIS OF ELLIPTICAL ECCENTRICITY 0.8: (A)FORMING LIMIT DIAGRAM, (B) THICKNESS CHART

TABLE VI. EFFECT OF ELLIPTICAL ECCENTRICITY E ON STAMPING FORMABILITY

\begin{tabular}{|c|c|c|c|c|}
\hline Rarameter(\%) & $\begin{array}{c}\dot{\varepsilon}_{1} \\
\text { (Max } \\
\text { thinning } \\
\text { rate) }\end{array}$ & $\begin{array}{c}\dot{\varepsilon}_{2} \\
\text { (Max } \\
\text { thickening } \\
\text { rate) }\end{array}$ & $\begin{array}{c}\boldsymbol{E}_{\max } \\
\text { (max } \\
\text { principal } \\
\text { strain) }\end{array}$ & $\begin{array}{c}\Delta \Gamma \\
\text { (Material } \\
\text { flow } \\
\text { difference) }\end{array}$ \\
\hline 0.8 & 17.74 & 3.45 & 0.16 & 1.78 \\
\hline 0.6 & 10.42 & 3.93 & 0.11 & 0.98 \\
\hline 0.44 & 14.44 & 1.90 & 0.12 & 0.56 \\
\hline
\end{tabular}




\section{CONCLUSION}

After the analysis of punch radius (R), blank holder force (BHF) and friction coefficient (U), stamping speed (V) and ellipticity (E), the following rules of ellipse drawing can be drawed.

- The maximum thinning is always focused on the punch fillet area of the long axis of the ellipse, and easy to rupture firstly. Serious wrinkle site focuses on the discontinuities in short axis discontinuous area, and is prone to wrinkle. Not fully forms a long tail part in concentrated material plate, and the forming is not sufficient.

- The largest thinning rate of elliptical sheet increases nonlinearly with punch radius increasing; The maximum thickening rate decreased with punch radius value increasing; The maximum principal strain and punch radius had little effect; The material flow difference and punch radius showed a negative linear correlation, which reduces with the increasing of the punch radius.

- The relationship between maximum thinning rate and pressure is not completely linear, but the pressure decreased with the increase of BHF. The maximum thickness decreased when the BHF increasing. The maximum principal strain and material flow difference are little effected by BHF. Serious wrinkle region of elliptic drawing forming is decreasing with the increase of BHF.

- The maximum thinning rate increases with the increase of friction coefficient. The maximum thickening rate decreased with friction coefficient increasing. The material flow difference must be better with the increase of friction coefficient.

The maximum thinning rate is negatively correlated with the stamping speed, and the maximum thinning rate reduces with stamping speed increases. The maximum thickening rate and stamping speed also showed a negative correlation characteristic. The maximum principal strain and material flow difference are not obvious effected by tamping speed.

The relationship between the maximum thickness rate and ellipticity is nonlinear, which increases with ellipticity increasing. The maximum principal strain and eccentricity is nonlinear decreasing. Material flow difference and ellipticity are positively correlation, which decreases with ellipticity increasing. Forming wrinkle region significantly reduced with the ellipticity reducing. The forming process is more fully with the centrifugal rate decreased.

\section{ACKNOWLEDGMENT}

The National Natural Science Foundation of China (No. 51505408), Jiangsu province (policy guidance) research cooperation project of China(Grant NO. BY2016065-37).

\section{REFERENCES}

[1] Jingrong Xiao, Shangjian Li, "Similar conditions of rigid plastic deformation simulation," Journal of Huazhong University of Science and Technology. Wuhan, vol. 15, pp. 35-39, January 1987.
[2] Minghua Jia, Xianzhang Zeng, "Finite element analysis of a cup of composite extrusion of rigid plastic," Mold Technology. Shenzhen, pp. 1-11. May 1988.

[3] Huolun Xiong, "Computer aided analysis of simulation forming system ," Beijing University of Aeronautics and Astronautics. Beijing, pp. 5-9, 1990.

[4] JS Xia, SS Dou, "Experimental research on the flanging height adjustment based on environmental way," International Journal of Applied Environmental Sciences. Seoul, vol. 20, pp. 2470-2489, August 2013.

[5] Ling Jiang, "Finite element analysis and optimization design of cold forging die," China Science and Technology Information. Beijing, pp. 32-36, January 2006.

[6] Yang Yu, "Prediction of sheet metal stamping performance and Simulation of deep drawing based on Dynaform," Jilin University. Jilin, pp. 1-10, 2010.

[7] Xianwen Zhang, "Research and design of B column stamping die based on," Guangxi University of Science and Technology. Guangxi, pp. 5-12, 2013.

[8] Xiongfei Yin, You Ye, "Calculated time control of sheet metal forming in numerical simulation," Mold Industry. Guilin, pp. 11-13, 1999.

[9] L. C. Sousa, C. F. Castro and C. A. C. Antonio, "Optimal Design of V and U Bending Processes Using Genetic Algorithms," Journal of Material Processing Technology. Switzerland, vol. 172, pp. 35-41, 2006.

[10] G. Liu, Z. Lin, W. Xu and Y. Bao, "Variable Blankholder Force in UShaped Part Forming for Elimination Springback Error," Journal of Material Processing Technology. Switzerland, vol.120, pp. 259-264, 2002.

[11] Samuel M, "Experimental and numerical prediction of springback and side wall curl in u-bending of anisotropic sheet metal," Journal of Materials Processing Technology. Switzerland, vol.105, pp. 382-393, 2003. 